\title{
Potato Plants Genetically Modified to Produce N-Acylhomoserine Lactones Increase Susceptibility to Soft Rot Erwiniae
}

\author{
I. K. Toth, ${ }^{2}$ J. A. Newton, ${ }^{1}$ L. J. Hyman, ${ }^{2}$ A. K. Lees, ${ }^{2}$ M. Daykin, ${ }^{3}$ C. Ortori, ${ }^{3}$ P. Williams, ${ }^{3}$ and R. G. Fray ${ }^{1}$ \\ ${ }^{1}$ School of Biological Sciences, Nottingham University, Sutton Bonington Campus, Loughborough LE12 5RD, U.K.; ${ }^{2}$ Scottish \\ Crop Research Institute, Invergowrie, Dundee DD2 5DA, U.K.; Institute of Infection, Immunity and Inflammation, Centre for \\ Biomolecular Sciences, University of Nottingham, University Park, Nottingham NG7, U.K.
}

Submitted 7 August 2003. Accepted 16 March 2004.

\begin{abstract}
Many gram-negative bacteria employ $N$-acylhomoserine lactones (AHL) to regulate diverse physiological processes in concert with cell population density (quorum sensing [QS]). In the plant pathogen Erwinia carotovora, the AHL synthesized via the carI/expI genes are responsible for regulating the production of secreted plant cell walldegrading exoenzymes and the antibiotic carbapen-3-em carboxylic acid. We have previously shown that targeting the product of an AHL synthase gene (yenI) from Yersinia enterocolitica to the chloroplasts of transgenic tobacco plants caused the synthesis in planta of the cognate AHL signaling molecules $N$-(3-oxohexanoyl)-L-homoserine lactone (3-0xo-C6-HSL) and $N$-hexanoylhomoserine lactone (C6-HSL), which in turn, were able to complement a $\mathrm{carI}^{-}$ QS mutant. In the present study, we demonstrate that transgenic potato plants containing the yenI gene are also able to express AHL and that the presence and level of these AHL in the plant increases susceptibility to infection by $E$. carotovora. Susceptibility is further affected by both the bacterial level and the plant tissue under investigation.
\end{abstract}

Regulation of bacterial metabolism by the production of $\mathrm{N}$ acylhomoserine lactones (AHL) occurs in many different species of gram-negative bacteria (Loh et al. 2002; Miller and Bassler 2001; Swift et al. 2001; von Bodman et al. 2003; Whitehead et al. 2001). AHL are produced in small amounts by bacteria but accumulate as the bacterial population grows. Upon reaching a critical population level (a point at which the population is said to be "quorate"), a synchronous, community-wide response can be induced by the bacteria in response to the AHL, triggering expression of certain genes. Behavior associated with AHL production includes stationary phase induction (Lithgow et al. 2000), pathogenesis (Williams et al. 2000; Wu et al. 2001), biofilm formation (De Kievit et al. 2001), antibiotic production (Bainton et al. 1992), exoenzyme production (Chernin et al. 1998), nodulation (Rosemeyer et al. 1998), plasmid transfer (Piper and Farrand 2000), and light production. In Erwinia carotovora, AHL are synthesized by the luxI homologue carI (Swift et al. 1993) (equivalent to expI; Pirhonen et al. 1993) and are involved in the regulation of plant cell wall degrading enzymes (PCWDE), virulence, and the production of the antibiotic carbapen-3-em carboxylic acid (Jones et al. 1993; Swift et al. 1993).

Corresponding author: R. G. Fray; E-mail: rupert.fray@nottingham.ac.uk
We previously showed the feasibility of synthesizing bacterial AHL signaling molecules in planta, using transgenic tobacco plants that expressed the yenI gene from Yersinia enterocolitica (Fray et al. 1999). In both Y. enterocolitica and yenIexpressing Escherichia coli, this gene product directs the synthesis of C6-HSL and 3-oxo-C6-HSL in a 1:1 ratio (Throup et al. 1995). The transgenic tobacco plants produced the predicted AHL in the same ratio and at biologically active levels but only when YenI was targeted to the chloroplasts (Fray et al. 1999). This requirement for plastid location is probably due to the availability in this organelle of the immediate precursors for AHL synthesis. The AHL-producing tobacco plants were able to restore pathogenicity to an avirulent E. carotovora subsp. carotovora carI $^{-}$mutant, showing that AHL production could directly influence the activity of the pathogen in planta (Fray et al. 1999).

Mäe and associates (2001) were also able to partially complement an E. carotovora subsp. carotovora expI mutant by showing a transient restoration of growth within AHL-producing tobacco plants (the identity of one or more AHL was not confirmed but was believed to be 3-oxo-C6-HSL or one or more closely related molecules). However, these workers also showed that, at an initial bacterial cell population density of 2 $\times 10^{6} \mathrm{CFU}$ per inoculation site, host resistance was higher in both the 3-oxo-C6-HSL-producing tobacco plants and upon exogenous addition of 3-oxo-C6-HSL to the leaf surface. These results support a model for the role of quorum sensing (QS) in the production of PCWDE and possibly other virulence factors during infection. At low bacterial cell densities, the AHL are below QS levels, PCWDE are not produced, and the bacteria are able to multiply without triggering plant defenses. At higher cell densities, QS is activated and PCWDE are produced, but although the cell wall breakdown products resulting from the enzyme attack trigger plant defenses, these defenses are insufficient to prevent the onset of disease. Were AHL to be present at low bacterial cell densities, the production of PCWDE and other virulence factors would be insufficient to overcome plant defenses, and disease would be arrested (Mäe et al. 2001; Salmond et al. 1995).

To further support the role of AHL in the infection process, tobacco and potato plants were engineered to produce a lactonase from Bacillus cereus, which renders AHL inactive by hydrolyzing the homoserine lactone ring (Dong et al. 2001). In both plants, host resistance was greatly enhanced upon infection by E. carotovora, being greater in transgenic plants exhibiting higher levels of lactonase expression or where lower levels of inocula were applied (down to $10^{3} \mathrm{CFU}$ per inoculation site). 
In light of the above observations and the perceived importance of different AHL levels and bacterial cell population densities, we re-examined the effects of AHL production on disease development in potato following inoculation with different E. carotovora subsp. atroseptica and E. carotovora subsp. carotovora strains.

\section{RESULTS}

\section{Generation of AHL-producing potato plants.}

The plastid-targeted yenI gene construct (Fray et al. 1999) was used to transform potato plants (cultivar Desirée). AHL production in the transgenic plants was confirmed by the ability of these plants to induce light output and violacein production in the AHL biosensors E. coli [pSB401] (Fig. 1A) and Chromobacterium violaceum CVO26, respectively (Fig. 1B). Based on these results, two transformed potato plants, YI5A and YIB6, were then used for further study. When extracts of the transgenic AHL-producing plants were subjected to thin-layer chromatography (TLC) and were overlaid with the CVO26 biosensor, two different AHL molecules with retention factor (Rf) values identical to those of synthetic 3oxo-C6-HSL, and C6-HSL standards were observed (Fig. 2). However, the spot corresponding to 3-oxo-C6-HSL was only apparent when high concentrations of the plant extract were loaded. This can only be partially explained by the lower sensitivity of this biosensor for 3-oxo-C6-HSL relative to C6-HSL and indicates that the two molecules are not being produced in a 1:1 ratio in potato. Dilution of the extracts to a point at which only C6-HSL was detectable by the biosensor strain allowed an estimation of C6-HSL levels in various organs of the two transgenic plants. A dilution series against a C6-HSL standard was carried out in microtiter plates to determine the point at which no violacein production resulted. Stems contained approximately 10 times more C6-HSL than that in tubers (on a fresh weight basis), and YI5A produced approximately 10 times more C6-HSL than did YIB6 (in stems YI5A $=0.35$, YIB6 $=0.024$; tubers YI5A $=0.032$, YIB6 $=0.0025 \mu \mathrm{g}$ per $\mathrm{g}$ of fresh weight). The lower "apparent" levels of C6-HSL in tubers may reflect a lower level of synthesis in amyloplasts than chloroplasts. In addition, tuber tissue is inherently denser than stem tissue, and values expressed on a fresh weight basis are thus not directly comparable between these organs. When the potato AHL extracts were analyzed by liquid chromatography (LC)-tandem electrospray mass spectrometry, the presence of C6-HSL and 3oxo-C6-HSL was confirmed, and the transgenic plants were also found to be producing traces of the closely related AHL, $\mathrm{N}$-(3-oxo-octanoyl) homoserine lactone (3-oxo-C8-HSL).

\section{Production of AHL by E. carotovora strains.}

TLC of culture supernatant extracts from all strains used in the study showed that they each produced at least one AHL capable of activating the CVO26 biosensor (Fig. 3). This transactivation, together with the Rf values, is indicative of AHL with acyl side chains between six and eight carbons in length. Such related AHL usually cross-activate, as appears to be the case here. Subsequent LC-tandem electrospray mass spectrometry of these extracts confirmed the presence of 3-oxo-C6-HSL in all strains, with the exception of $E$. $c a$ rotovora subsp. carotovora SCC 3193. All bacterial strains were also found to produce 3-oxo-C8-HSL. E. carotovora subsp. carotovora SCRI 193 and SCRI 212 as well as E. carotovora subsp. atroseptica SCRI 1043 produced C6-HSL, while E. carotovora subsp. carotovora SCRI 3193, E. carotovora subsp. atroseptica SCRI 41, and E. carotovora subsp. atroseptica SCRI 1039 extracts all appeared to contain C8HSL. In the case of E. carotovora subsp. carotovora SCRI 193, preliminary evidence for the presence of C7-HSL was also found. Thus, all of the bacterial strains employed utilize AHL that are identical to those found in the transgenic potato plants. In some cases, strains may also produce very closely related AHL analogues, which would be anticipated to exhibit cross talk within this system.
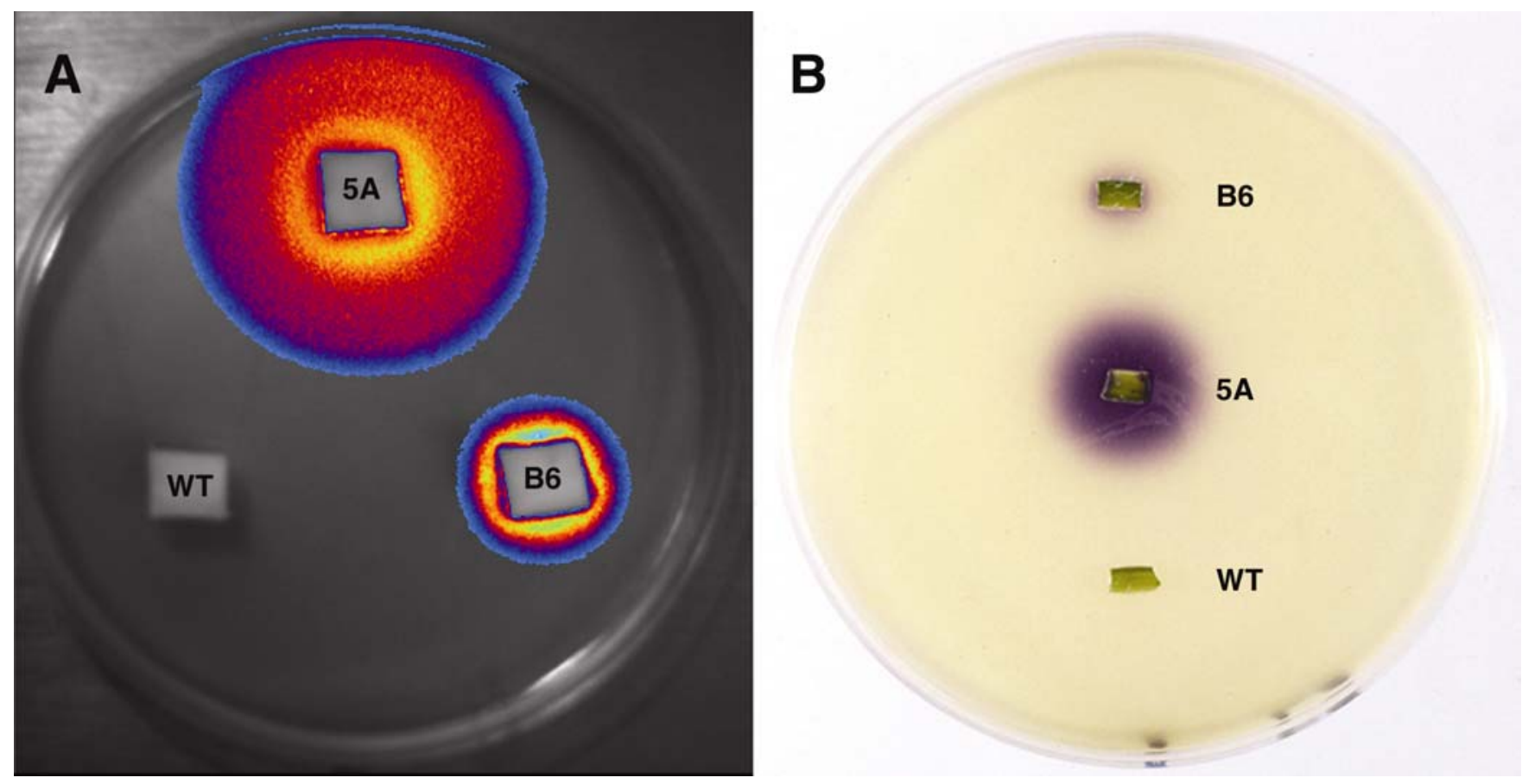

Fig. 1. $N$-acylhomoserine lactone (AHL) assay on transgenic potato lines YIA5 and YIB6 using A, tuber pieces and $\mathbf{B}$, stem segments. The presence of AHL is indicated by light production (shown in false color) or by the induction of a purple pigment violacin in the biosensor strains Escherichia coli [pSB401] and Chromobacterium violaceum CV026 (A and B, respectively). YI5A produces approximately 10 times more AHL than does YIB6. 


\section{Stem inoculation tests.}

E. carotovora subsp. atroseptica SCRI 1039 was inoculated into potato stems at various cell population densities and, based on these results, two further E. carotovora subsp. atroseptica strains and three E. carotovora subsp. carotovora strains were inoculated into stems at a single cell population density. In the untransformed cultivar Desirée (control) and the transgenic plants YI5A and YIB6, no observable differences in disease development were seen when E. carotovora subsp. atroseptica SCRI 1039 was inoculated into stems at or above $10^{6}$ cells per inoculation site. In such cases, disease was visible two days after inoculation and was developed to similar levels (data not shown). However, differences in disease development (both the severity of disease and the time of disease onset) were seen both between the transgenic plants and between these plants and the control as the level of inoculum was reduced (Fig. 4). The onset of disease development (appearing within two days of inoculation) and disease progression were initially similar in all plants at $10^{5}$ E. carotovora subsp. atroseptica SCRI 1039 CFU per inoculation site. However, from day 5 and 6 onward, YI5A and YIB6, respectively, developed a similar level of disease, which was significantly higher than the control. At $10^{3}$ E. carotovora subsp. atroseptica SCRI 1039 CFU per inoculation site, disease onset was similar in both YI5A and YIB6, but as disease progressed, it became more severe in YI5A than in YIB6 (Fig. 4). At this inoculum level, disease onset and incidence were dramatically reduced in the control compared with either transgenic line, becoming significantly different at days 3 and 4, for YI5A and YIB6, respectively. At $10^{2}$ E. carotovora subsp. atroseptica SCRI 1039 CFU per inoculation site, the disease severity was not significantly different between YI5A and YIB6 throughout the 10 days, although disease appeared earlier in YI5A. Again, little disease was seen in the control plants, being significantly less than YI5A and YIB6 by day 6 and 7, respectively. At $10^{2}$ E. carotovora subsp. atroseptica SCRI 1039 CFU per inoculation site, disease severity was significantly less than at $10^{3}$ E. carotovora subsp. atroseptica SCRI 1039 CFU per inoculation site by day 3 and 4 for YI5A and YIB6, respectively, and remained so.

To ensure that the results obtained for E. carotovora subsp. atroseptica SCRI 1039 were not strain specific, a further two E. carotovora subsp. atroseptica and three E. carotovora subsp. carotovora strains were stab-inoculated into stems of YIB6 and the control at a cell population density equivalent to that showing the largest difference in disease onset and severity for strain $E$. carotovora subsp. atroseptica SCRI 1039, i.e., $10^{3} \mathrm{CFU}$ per inoculation site. As expected, strains E. carotovora subsp. atroseptica SCRI 1043 and E. carotovora subsp. atroseptica SCRI 41 gave essentially similar results to $E$. carotovora subsp. atroseptica SCRI 1039 (Fig. 5). Results from the E. carotovora subsp. carotovora-inoculated YIB6 stems showed less disease than the E. carotovora subsp. atrosepticainoculated stems but again, more disease was seen in YIB6 than in the control, in which no disease was recorded (Fig. 5). The difference in pathogenicity between the E. carotovora subsp. atroseptica and E. carotovora subsp. carotovora strains may have been a consequence of the plant assay used, which was developed primarily for studies on E. carotovora subsp. atroseptica (Lapwood and Read 1986).

\section{Tuber inoculation tests.}

Tubers of the transgenic plants YI5A and YIB6, vacuuminfiltrated with $10^{6}$ E. carotovora subsp. atroseptica SCRI $1039 \mathrm{CFU} \mathrm{m}^{-1}$ (equivalent to approximately $10^{4}$ cells per tuber), showed significantly more disease than the control (Fig. $6 \mathrm{~A})$. Although there was no significant difference in the sever- ity of soft rot symptoms between YI5A and YIB6, the former had a higher average disease severity.

Following stab-inoculation of tubers at $10^{6} \mathrm{E}$. carotovora subsp. atroseptica SCRI 1039 CFU per inoculation site, YI5A and YIB6 again showed a significant increase in disease compared with the control four days after inoculation (Fig. 6B). At $10^{5}$ E. carotovora subsp. atroseptica CFU per inoculation site, YI5A showed a significant increase in disease three and four days after inoculation, compared with the control and YIB6, respectively. At all other times and inoculum cell population densities, there were no differences in disease development between the three sets of test tubers. As inoculations at $10^{4} \mathrm{E}$. $\mathrm{ca}$ rotovora subsp. atroseptica $\mathrm{CFU}$ per inoculation site were not significantly different from inoculation with $\mathrm{MgSO}_{4}$, no further $E$. carotovora subsp. atroseptica dilutions were tested.

\section{DISCUSSION}

AHL play an important role in the cell-density-dependent regulation of virulence and other factors in bacteria (Loh et al. 2002; Miller and Bassler 2001; Swift et al. 2001; von Bodman et al. 2003; Whitehead et al. 2001). In the soft rot erwiniae, this cell population-density dependent signaling coordinates the production of PCWDE and possibly other virulence factors that lead to tissue maceration and disease development. The current QS model has been a useful tool in developing our understanding of the infection process (Mäe et al. 2001; Salmond et al. 1995). However, data supporting it is largely circumstantial, and it fails to take into account important events during the early Erwinia-plant interaction that, in addition to the production of PCWDE, may affect disease development such as reduced oxygen levels, an increase in available free water, and the production of factors involved in host recognition (e.g., type III effectors) (Galan and Collmer 1999; Perombelon 2002).

In this study, we observed the effects of AHL production in planta following inoculation with E. carotovora subsp. atro-

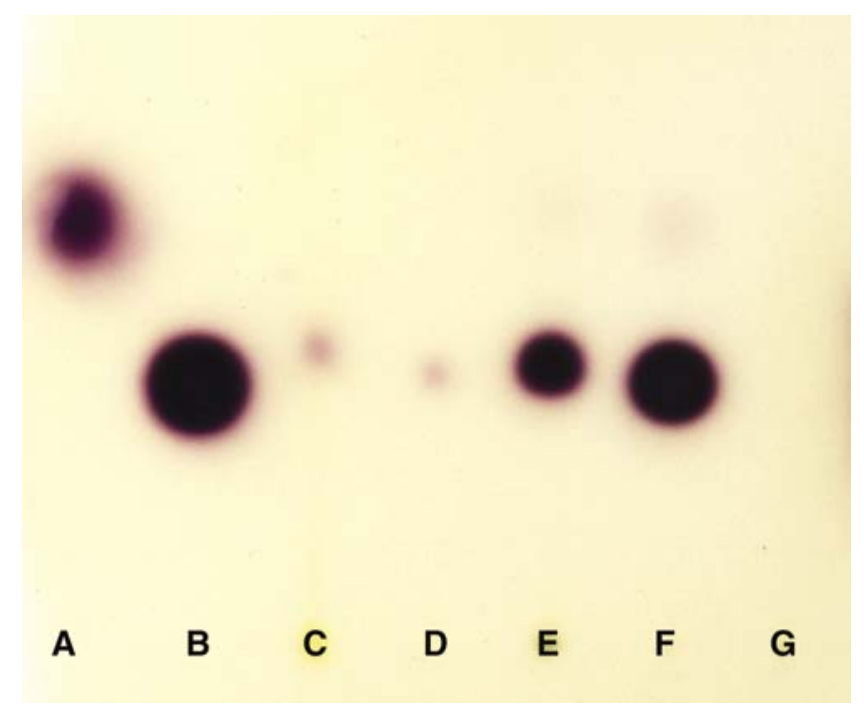

Fig. 2. Thin-layer chromatography of potato plant extracts overlain with the CV026 N-acylhomoserine lactone (AHL) biosensor strain, the presence of AHL is indicated by the induction of violacin synthesis. The transgenic plant extracts contain AHL with retention factor values identical to those of 3-oxo-C6HSL (lane A) and C6-HSL (lane B) standard controls. Extracts are from B6 tuber (lane C), YI5A tuber (lane D), YIB6 stem (lane E), YI5A stem (lane F), and wild-type control stem (lane G). For YIB6 samples the amount of extract loaded is the equivalent of $1 \mathrm{~g}$ of starting material; for YI5A and the wild-type samples, the equivalent of $0.1 \mathrm{~g}$ of starting material has been loaded. 
septica or E. carotovora subsp. carotovora at bacterial population densities ranging from $10^{2}$ to $10^{6} \mathrm{CFU}$ per inocuation site, as these levels are likely to be associated with early and late infection, respectively (Perombelon 2002; Perombelon et al. 1979). We constructed transgenic potato plants expressing the yenI gene from Yersinia enterocolitica and demonstrated, using TLC and AHL biosensors in conjunction with high resolution LC-tandem mass spectrometry, that these plants were producing 3-oxo-C6-HSL and C6-HSL (Figs. 1 and 2) as well as 3-oxo-C8-HSL. (Figs. 1 and 2). We also showed that these AHL include the cognate AHL for E. carotovora subsp. atroseptica SCRI 1039 and other strains used in the study (Fig. 3). Following potato stem and tuber inoculations, progressively more disease development was seen in the transgenic potatoes than in the control plants as the level of bacterial inoculum in the plants was reduced (Figs. 4 through 6). Moreover, increased levels of AHL in planta increased both the onset and severity of disease. Previously, we determined that the equivalent AHL-producing construct in transgenic tobacco plants was able to complement an E. carotovora subsp. carotovora carl $^{-}$mutant (Fray et al. 1999). Together, these data suggest that the in planta-produced AHL act directly on the QS regulon in the pathogen, accelerating both the production of PCWDE (and possibly other factors) and disease development, even from low initial bacterial cell population densities. Interestingly, although increased susceptibility was observed in both potato tubers and stems expressing AHL, differences in susceptibility at higher cell population densities were more apparent in tubers (Figs. 4 through 6). This may reflect the lower levels of AHL expression or availability in tubers or simply differences in the sensitivities of the stem and tuber assays used.

In contrast to the QS model, the production of PCWDE at low bacterial cell population densities in the transgenic potato plants failed to switch on plant defenses sufficient to prevent infection. Plant cell-wall breakdown products generated by PCWDE are known to switch on these defenses (Dellagi et al. 2000; Palva et al. 1993). It is thus likely that prior to the natural induction of the PCWDE in potato, plant defenses are in some way repressed; an event not taken into account in the current model. For example, this is known to occur through oxygen limitation, a prerequisite to successful infection by the soft rot erwiniae, which reduces oxygen-depen- dent resistance mechanisms in the plant (Perombelon 2002). Low oxygen concentrations occurring at the time of pathogen invasion may also retard or prevent lignification and suberization of plant tissues, both of which would offer further protection against attack by the PCWDE (Perombelon 2002; Thomson et al. 1995). Such an effect, however, may still not offer sufficient protection to the invading pathogen, particularly at low cell population densities. Defenses may thus need to be further reduced and, possibly, other cellular responses affected in the plant prior to or together with the induction of PCWDE for a successful infection to occur, e.g., through the action of type III and other effectors (Galan and Collmer 1999). This is supported by evidence that the QS regulon may act on the type III secretion system as well as PWCDEs (Mukherjee et al. 1997; von Bodman 2003). It is thus possible that the QS regulon in planta is involved in the determination of a host/nonhost interaction based on the production of these effectors. The need for one or more host recognition events prior to the production of PCWDE in the host plant is further supported by data showing that an exogenous addition of AHL to E. carotovora cultures in vitro at low cell densities fails to trigger the production of PCWDE, at least in some strains (including some used in this study) (G. P. C. Salmond, unpublished data). Finally, in planta production of AHL in this study led to increased disease development from bacterial populations as low as $10^{2}$ cells per inoculation site. Thus the coordinate production of PCWDE at high bacterial populations may simply be a response to nutrient limitation rather than a mechanism to overcome plant defenses.

In conclusion, we have shown that the presence of AHL in transgenic potato plants inoculated with E. carotovora cells, even at low cell population densities, increases disease development. Our data thus suggest that the role of density-dependent PCWDE regulation is probably not a means of avoiding plant defenses but, more likely, simply a mechanism to increase nutrient availability at the later stages of infection. We also suggest that the production of PCWDE via the QS system is unlikely to occur in natural infections before the host or nonhost status of the plant has been established. We are currently investigating the temporal production of type III effectors and PCWDE in planta and their relationship to the QS regulon during the infection process.
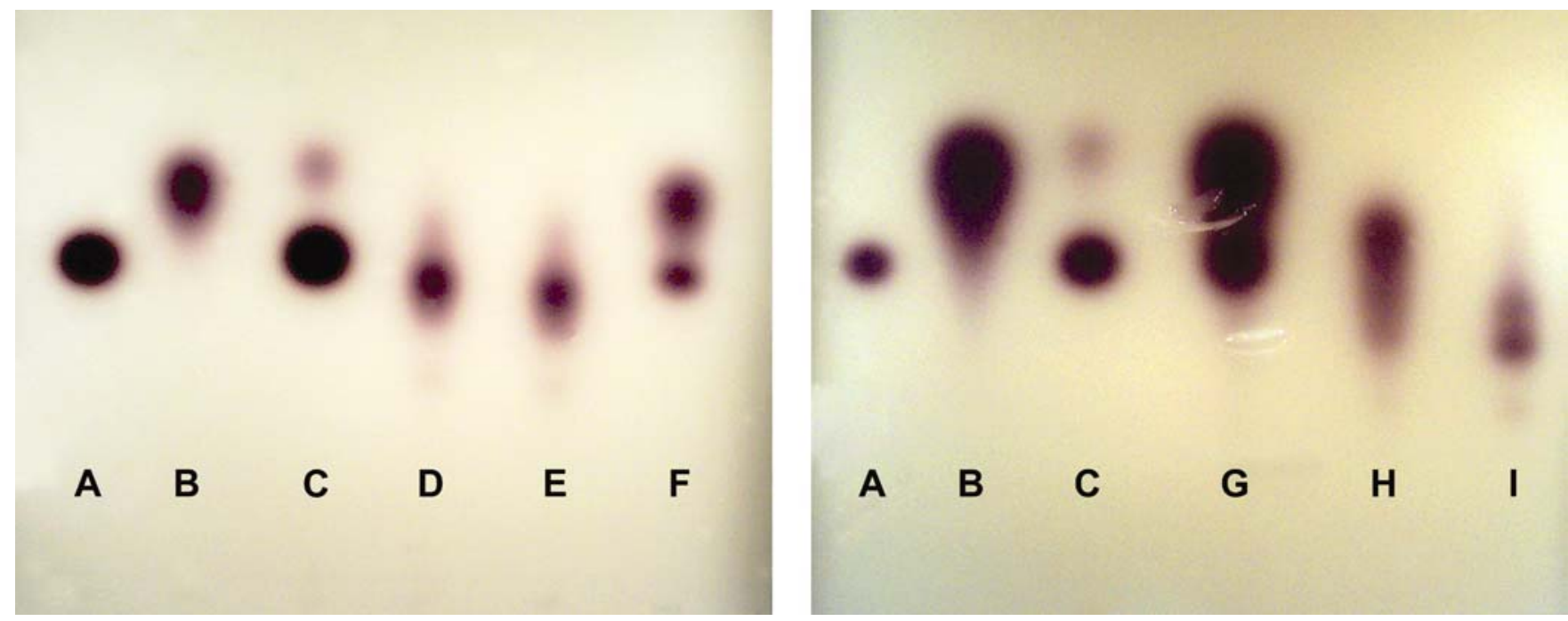

Fig. 3. $\mathrm{N}$-acylhomoserine lactone (AHL) profiles of soft rot Erwinia species. Thin-layer chromatograms of spent culture supernatant extracts were overlain with the CV026 AHL biosensor. Lane A, C6-HSL; lane B, 3-oxo-C6-HSL; lane C, YI5A leaf extract; lanes D through F, Erwinia carotovora subsp. atroseptica SCRI 41, SCRI 1039, and SCRI 1043; lanes G through I, Erwinia carotovora subsp. carotovora SCRI 193, SCRI 212 , and SCC 3193. 


\section{MATERIALS AND METHODS}

Generation of transgenic plants.

The binary plant transformation vector pBDHERBYI (Fray et al. 1999) in Agrobacterium tumefaciens LBA4404 was used to transform stem sections of aseptically grown potato (cultivar Desirée), according to standard protocols (Draper et al. 1988). The transgenic status of the resulting kanamycin positive explants was confirmed by Southern analysis (data not shown). From eight positive transgenic lines, a high and a relatively low AHL producer were chosen for propagation and further study.

\section{Extraction and TLC analysis of AHL.}

For TLC analysis, transgenic plant extracts were prepared by grinding plant tissue $(2 \mathrm{~g})$ in methanol (at least $5 \mathrm{ml}$ ), and the liquid extract was collected, and the remaining tissue reextracted with fresh methanol. This procedure was repeated a minimum of four times, until no more pigments could be extracted. The methanol extracts were pooled and adjusted to $60 \%$ methanol by adding sterile distilled water (in calculating the amount of water added, it was assumed that for a starting tissue mass of $2 \mathrm{~g}, 2 \mathrm{ml}$ of water had already been contributed to the extract). The $60 \%$ methanol extract was held at $-20^{\circ} \mathrm{C}$ for $2 \mathrm{~h}$ to precipitate the majority of the chlorophyll, which was then removed by centrifugation at 3,000 rpm in a bench top centrifuge for $10 \mathrm{~min}$. The solution was then extracted five times with half volumes of dichloromethane. The dichloromethane extracts were pooled and evaporated to dryness, and the residue was taken up in $200 \mu$ of acetonitrile. Samples of these extracts were applied to a C18 reverse-phase TLC plate
(Merck, Darmstadt, Germany). A similar extract from an untransformed plant was also spotted onto the plate. C6-HSL (10 ng) and 3-oxo-C6-HSL (50 ng) were applied as standards, and the chromatogram was developed with methanol/water (60:40 $\mathrm{vol} / \mathrm{vol}$ ) as running solvent. After drying, AHL were located on the TLC plate by overlaying with either E. coli [pSB401] or $C$. violaceum $\mathrm{CVO} 26$ in top agar. After $16 \mathrm{~h}$ growth at $28^{\circ} \mathrm{C}$, the presence of AHL was indicated by bioluminescence (Winson et al. 1998) or violacein production (McClean et al. 1997).

\section{AHL identification}

by LC-tandem electrospray mass spectrometry.

An Agilent 1100 series vacuum degasser, autosampler, and binary capillary LC pump was used in line with a Waters Micromass Quattro Ultima mass spectrometer. Injections $(5 \mu \mathrm{l})$ were applied to a C8 column (Kromasil $5 \mu \mathrm{m} 250 \times 2.1 \mathrm{~mm}$; Jones Chromatography, Ponypridd, U.K.) and were eluted using a linear acetonitrile in water gradient, 20 to $100 \%$ over 10 min. After $10 \mathrm{~min}$ at $100 \%$ acetonitrile, the column was reequilibrated. The LC system was directly coupled to the mass spectrometer probe, without splitting the $0.200 \mathrm{ml}$ per min flow. Synthetic standards of the C4-, C6-, and C8- unsubstituted, 3-oxo-, and 3-hydroxy AHL at $1 \mathrm{ug} / \mathrm{ml}$ were used throughout. These were synthesized as described before (Chhabra et al. 1993, 2003).

For each compound, the following $[\mathrm{M}+\mathrm{H}]^{+}$parent ions were selected, using the minimum cone voltage (35 V): C4-HSL, 172; 3-oxo-C4-HSL and -C5-HSL, 186; 3-hydroxy C4-HSL, 188; C6-HSL, 200; 3-oxo-C6-HSL and -C7-HSL, 214; 3-hydroxy-C6-HSL, 216; 3-oxo-C7-HSL and -C8-HSL, 228, 3-

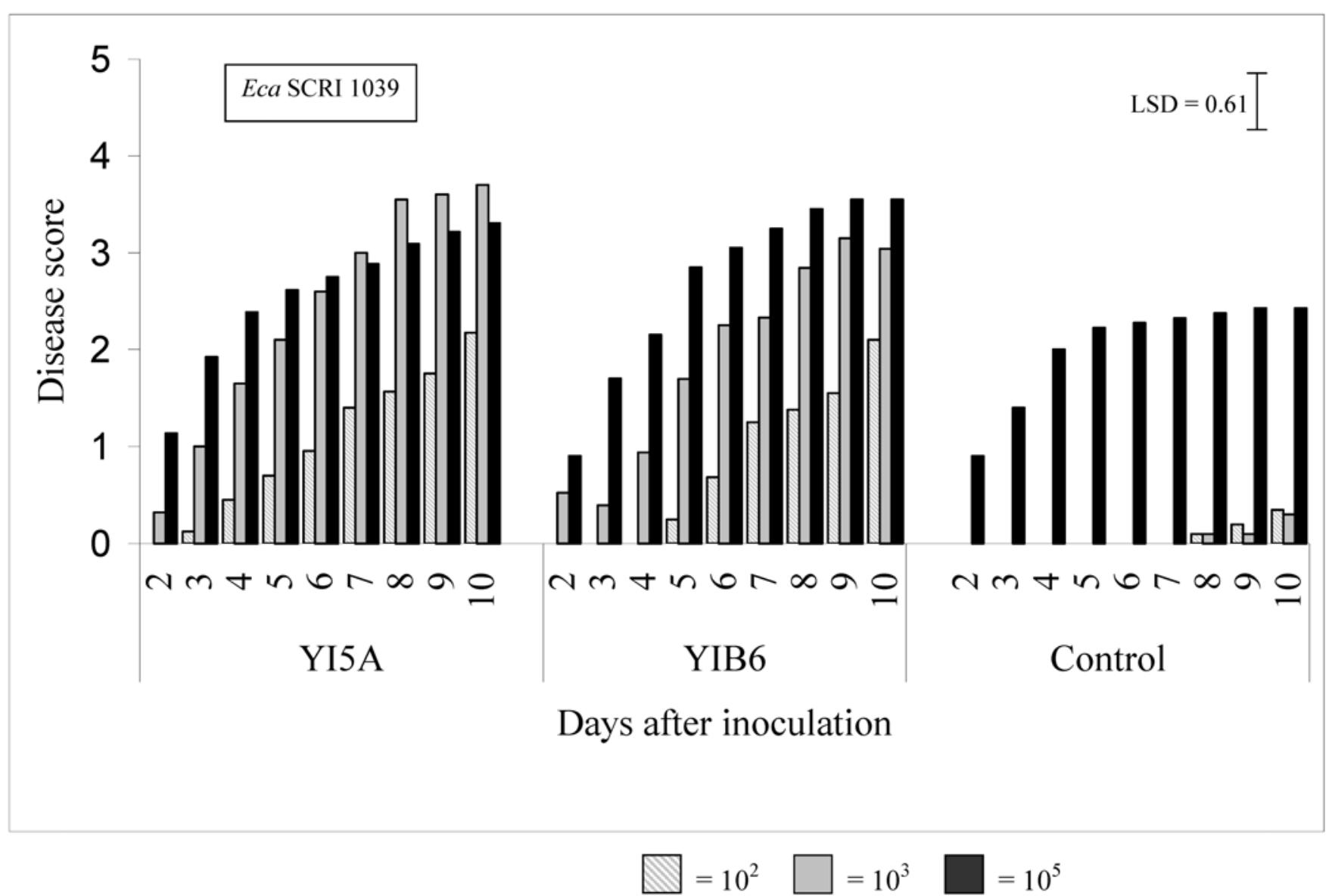

Fig. 4. Stem disease scores determined between 2 and 10 days postinoculation with varying concentrations of Erwinia carotovora subsp. atroseptica (Eca) SCRI 1039 ranging from $10^{2}$ to $10^{5} \mathrm{CFU}$ per inoculation site plus a $\mathrm{MgSO}_{4}$ control on transgenic potato lines YI5A and YIB6 and on the untransformed cv. Desirée control. 
oxo-C8-HSL, 242; and 3-hydroxy-C8-HSL, 244. The source and desolvation temperatures were 125 and $350^{\circ} \mathrm{C}$, respectively. Daughter ions of each of the anticipated AHL were monitored, using positive ion electrospray mode throughout each LC experiment. During each 1-s scan, the collision cell was ramped between 10 to $25 \mathrm{~V}$, and the helium collisioninduced dissociated gas was set at $5 \times 10^{-3}$ millibar. The instrument had been tuned such that the resolution was $0.7 \mathrm{Da}$ wide at half height. Each of the nine scan functions monitored daughter ions between 85 to $350 \mathrm{Da}$.

Sample AHL were identified and confirmed by producing extracted ion chromatograms of the 101.6-Da moiety corresponding to the homoserine lactone ring and comparing both the elution time and the spectra from any peaks obtained with those of the synthetic standards.

\section{Bacterial strains and media.}

E. carotovora subsp. atroseptica wild-type strains SCRI 1039, SCRI 1043, and SCRI 41 and E. carotovora subsp. carotovora wild-type strains SCC 3193 (Mäe et al. 2001), SCRI 193, and SCRI 212 were obtained from the SCRI culture collection from stocks stored in freezing medium at $-80^{\circ} \mathrm{C}$ and maintained on Luria Bertani (LB) agar at $27^{\circ} \mathrm{C}$.

\section{Potato stem resistance tests.}

Potato tubers of the control (cv. Desirée) and transgenic plants YI5A and YIB6 were grown for approximately 4 weeks in $15-\mathrm{cm}$ pots containing compost in a controlled environment glasshouse, with a $16-\mathrm{h}$ photoperiod at $22^{\circ} \mathrm{C}$. Stem inoculation was carried out when stems reached 30 to $40 \mathrm{~cm}$ in length. Bacterial inocula were prepared by growing the bacteria in LB broth at $27^{\circ} \mathrm{C}$ for $16 \mathrm{~h}$ with shaking. Bacterial cells were pelleted at $1,600 \times g$ for $5 \mathrm{~min}$ and then resuspended in the same volume of sterile $10 \mathrm{mmol}^{-1} \mathrm{MgSO}_{4}$. Optical density after diluting 1:10 was 0.25 at $600 \mathrm{~nm}$, approximately $2 \times 10^{8} \mathrm{CFU}$ $\mathrm{ml}^{-1}$. Decimal dilutions were prepared to $2 \times 10^{2} \mathrm{CFU} \mathrm{ml}{ }^{-1}$, and bacterial numbers were verified by viable counts on LB agar both before and following stem inoculation. On two separate occasions, at least 10 replicate potato stems were inoculated using a $100-\mu \mathrm{l}$ pipette tip containing $10 \mu \mathrm{l}$ of E. carotovora subsp. atroseptica SCRI 1039 at three different concentrations $\left(10^{4}, 10^{5}\right.$, or $\left.10^{7} \mathrm{CFU} \mathrm{m} \mathrm{m}^{-1}\right)$, equivalent to $10^{2}, 10^{3}, 10^{5}$ CFU per inoculation site. On a third occasion, all other strains (including SCRI 1039) were tested as above but on 13 replicate plants at $10^{5} \mathrm{CFU} \mathrm{m} \mathrm{m}^{-1}\left(10^{3} \mathrm{CFU}\right.$ per inoculation site) only. Stems were inoculated at the lower junction of the stem and the second leaflet from the top of the plant, in all cases. Control stems were inoculated with $10 \mu \mathrm{l}$ sterile $10 \mathrm{mmol} \mathrm{l}^{-1}$ $\mathrm{MgSO}_{4}$. The inoculation site was wrapped with nescofilm to seal the wound, and the plants were well watered and kept in a controlled environment glasshouse at $22^{\circ} \mathrm{C}$. Disease symptoms were assessed daily up to 11 days after inoculation, using a 0 to 5 scale of increasing disease severity: $0=$ no reaction; $1=$ slight browning around inoculation site; $2=$ slight blackening around inoculation site; $3=$ small black rot spreading from inoculation site; 4 = medium black rot spreading from inoculation site; and $5=$ large black rot accompanied by complete stem collapse (Toth et al. 1999).

\section{Potato tuber resistance tests.}

Potato tubers of the control, YI5A, and YIB6 were tested for resistance to E. carotovora subsp. atroseptica using two methods, vacuum infiltration of tubers with E. carotovora subsp. atroseptica SCRI $1039\left(10^{6} \mathrm{CFU} \mathrm{m}^{-1}\right)$ and stab-inoculation of whole tubers with E. carotovora subsp. atroseptica SCRI 1039 at various concentrations.

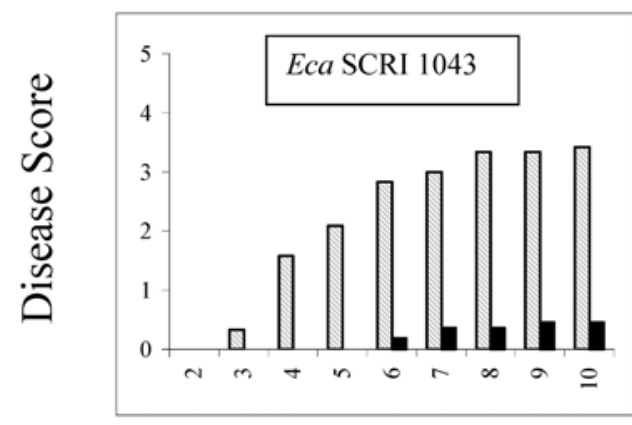

Days after inoculation

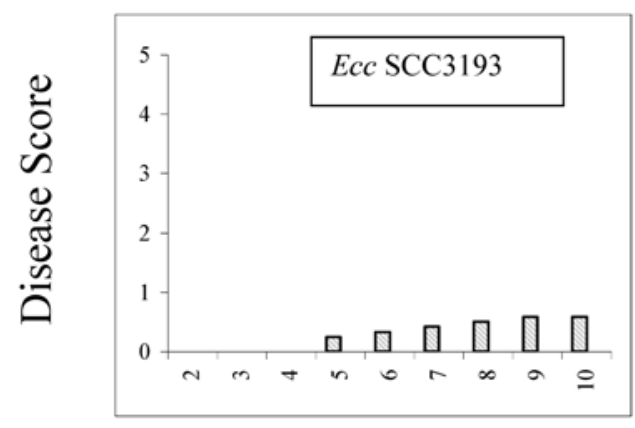

Days after inoculation

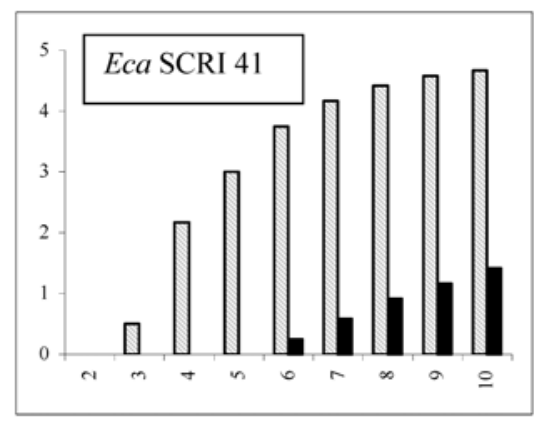

Days after inoculation

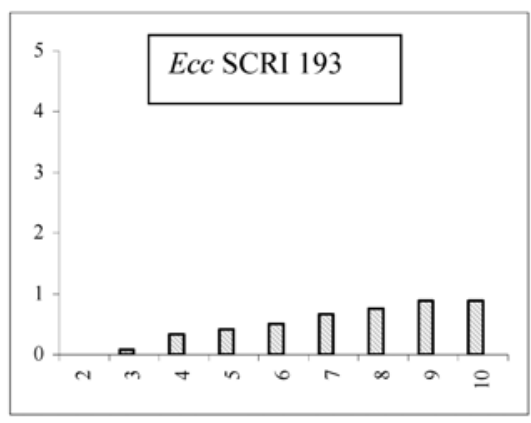

Days after inoculation

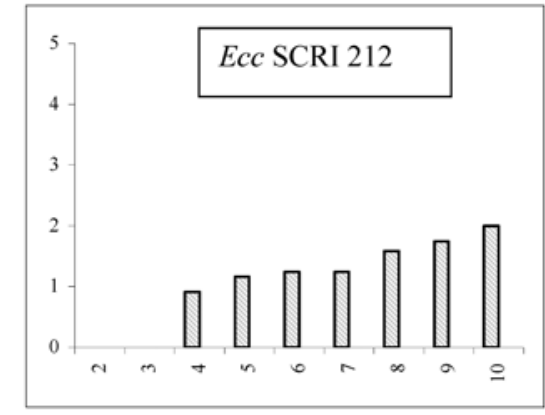

Days after inoculation

Fig. 5. Stem disease scores determined between 2 and 10 days postinoculation with $10^{3}$ CFU per inoculation site of Erwinia carotovora subsp. atroseptica (Eca) SCRI 1043 and SCRI 41 and Erwinia carotovora subsp. carotovora (Ecc) SCC 3193, SCRI 193, and SCRI 212 plus a MgSO 4 control on transgenic potato line YIB6 and the untransformed cv. Desirée control. 
Inoculum for vacuum infiltration was prepared by growing an overnight culture of $E$. carotovora subsp. atroseptica SCRI 1039 in $\mathrm{LB}$ broth shaken at $27^{\circ} \mathrm{C}$, before diluting with water to a final concentration of $4 \times 10^{6} \mathrm{CFU} \mathrm{ml}{ }^{-1}$. On two separate occasions, two replicates of five tubers were immersed in the inoculum and held under a vacuum at $-86 \mathrm{Kpa}$ for $5 \mathrm{~min}$ before restoring atmospheric pressure. Tubers were then placed on wet paper towels in 10-liter plastic boxes and were incubated immediately at $24^{\circ} \mathrm{C}$ and $95 \%$ relative humidity for five days. Replicates were arranged in a randomized complete block design. After incubation, each tuber was scored for disease, using a 0 to 4 scale of increasing susceptibility (De Maine et al. 1998).

For whole tuber stab-inoculations, tubers of the control, YI5A, and YIB6 were surface-sterilized with a 5\% sodium hypochlorite solution for $5 \mathrm{~min}$, were soaked, were washed twice in sterile water, and were air dried. E. carotovora subsp. atroseptica SCRI 1039 was grown and decimal dilutions were prepared as described for stem resistance tests. Tuber inoculation sites were prepared by stabbing the tuber to a depth of $7 \mathrm{~mm}$ with a premarked tip immediately before inoculation. At least 10 tubers and three replicate sites per tuber were inoculated with $10 \mu \mathrm{l}$ of E. carotovora subsp. atroseptica SCRI 1039 at one of three cell population densities $\left(10^{6}, 10^{7}\right.$, or $10^{8} \mathrm{CFU} \mathrm{ml} \mathrm{m}^{-1}$, equivalent to $10^{4}, 10^{5}$, or $10^{6}$ CFU per inoculation site), using a tip that was left in the inoculation site for the liquid to absorb. Control tubers were inoculated with $10 \mu \mathrm{l}$ of sterile $10 \mathrm{mmol} \mathrm{l}^{-1} \mathrm{MgSO}_{4}$. The tubers were incubated in a damp box at $24^{\circ} \mathrm{C}$ for four days, and the rot was assessed by measuring its depth and width

A

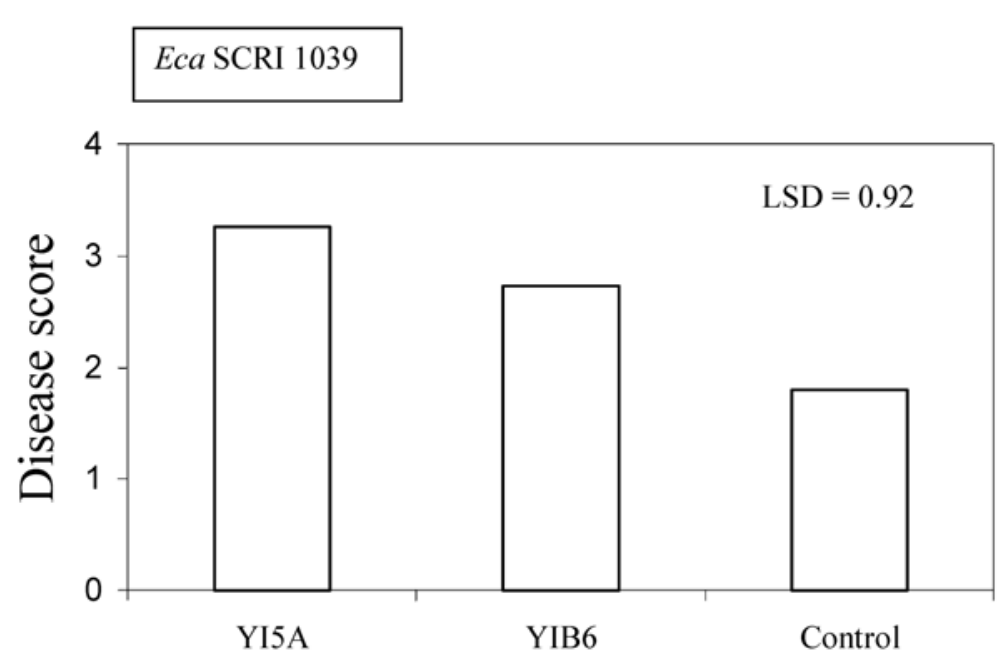

B

Eca SCRI 1039

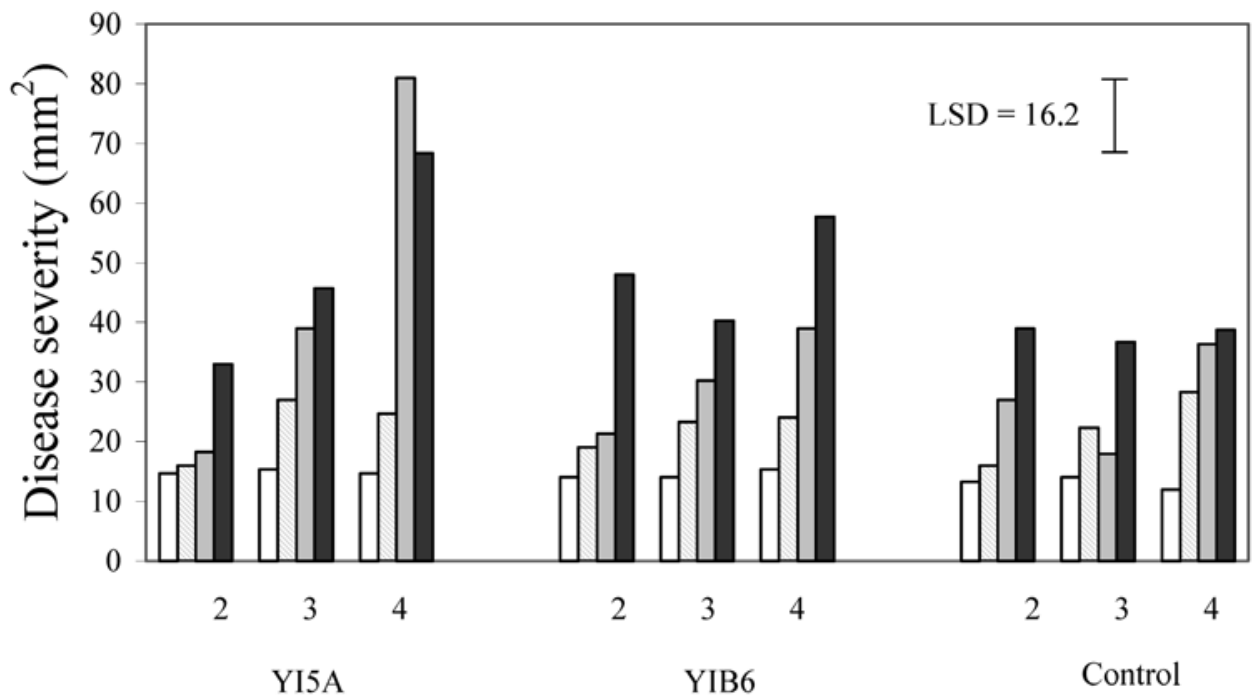

Days after inoculation

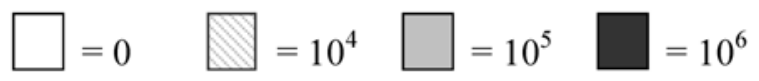

Fig. 6. A, Average disease score of tubers from transgenic potato lines YI5A and YIB6 and from the untransformed cv. Desirée control vacuum-infiltrated with Erwinia carotovora subsp. atroseptica (Eca) SCRI 1039 at $10^{6} \mathrm{CFU} \mathrm{m}{ }^{-1}$ and incubated for five days. B, Average disease severity in YI5A, YIB6, and untransformed control stab-inoculated with Erwinia carotovora subsp. atroseptica SCRI 1039 at various concentrations $\left(\mathrm{CFU} \mathrm{ml}^{-1}\right)$ and measured after two, three, and four days of incubation. 
(mm) two, three, and four days after inoculation by cutting open the inoculation site.

\section{Statistical analyses.}

Genstat for Windows version 6.1.0.200 (Genstat 6th edition, Lawes Agricultural Trust, Rothamsted, Hertfordshire, U.K.) was used for all statistical analyses (ANOVA; $P<0.05$ ).

\section{ACKNOWLEDGMENTS}

We thank P. Birch for helpful discussions and S. R. Chhabra for providing synthetic AHL. This work was supported by a Biotechnology and Biological Sciences Research Council Sir David Phillips Fellowship awarded to R. G. Fray, a European Framework Five grant QLK3-CT-2000-31759 awarded to R. G. Fray and P. Williams, and by The Scottish Executive Environment and Rural Affairs Department (I. K. Toth, L. J. Hyman, and A. K. Lees).

\section{LITERATURE CITATIONS}

Bainton, N. J., Stead, P., Chhabra, S. R., Bycroft, B. W., Salmond, G. P. C., Stewart, G. S. A. B., and Williams, S. P. 1992. N-(3-oxohexanoyl)L-homoserine lactone regulates carbapenem antibiotic production in Erwinia carotovora. Biochem. J. 288:997-1004.

Chernin, L. S., Winson, M. K., Thompson, J. M., Haran, S., Bycroft, B. W., Chet, I., Williams, P., and Stewart, G. S. A. B. 1998. Chitinolytic activity in Chromobacterium violaceum: Substrate analysis and regulation by quorum sensing. J. Bacteriol. 180:4435-4441.

Chhabra, S. R., Stead, P., Bainton, N. J., Salmond, G. P. C., Stewart, G. S. A. B., Williams, P., and Bycroft, B. W. 1993. Autoregulation of carbapenem biosynthesis in Erwinia carotovora by analogues of $\mathrm{N}$-(3-oxohexanoyl)-L-homoserine lactone. J. Antibiot. 46:441-454.

Chhabra, S. R., Harty, C., Hooi, D. S. W., Daykin, M., Williams, P., Pritchard, D. I., and Bycroft, B. W. 2003. Synthetic analogues of bacterial quorum sensing molecules as immune modulators. J. Med. Chem. 46:97-104.

De Kievit, T. R., Gillis, R., Marx, S., Brown, C., and Iglewski, B. H. 2001. Quorum-sensing genes in Pseudomonas aeruginosa biofilms: Their role and expression patterns. Appl. Environ. Microbiol. 67:1865-1873.

De Maine, M. J., Lees, A. K., and Bradshaw, J. E. 1998. Soft rot resistance combined with other tuber characters in long day-adapted Solanum phureja. Pot. Res. 41:69-82.

Dellagi, A., Heilbronn, J., Avrova, A. O., Montesano, M., Palva, E. T., Stewart, H. E., Toth, I. K., Cooke, D. E. L., Lyon, G. D., and Birch, P. R. J. 2000. A potato gene encoding a WRKY-like transcription factor is induced in interactions with Erwinia carotovora subsp. atroseptica and Phytophthora infestans and is coregulated with class I endochitin expression. Mol. Plant Microbe Interact. 13:1092-1101.

Dong, Y. H., Wang, L. H., Xu, J. L., Zhang, H. B., Zhang, X. F., and Zhang, L. H. 2001. Quenching quorum-sensing-dependent bacterial infection by an $N$-acyl homoserine lactonase. Nature 411:813-817.

Draper, J., Scott, R., and Hamil, J. 1988. Transformation of dicotyledonous plant cells using the Ti plasmid of Agrobacterium tumefaciens and the Ri plasmid of A. rhizogenes. Pages 69-160 in: Plant Genetic Transformation and Gene Expression: A Laboratory Manual. J. Draper, R. Scott, P. Armitage, and R. Walden, eds. Blackwell Scientific Publications. London.

Fray, R. G., Throup, J. P., Daykin, M., Wallace, A., Williams, P., Stewart, G. S. A. B., and Grierson, D. 1999. Plants genetically modified to produce $N$-acylhomoserine lactones communicate with bacteria. Nature Biotechnol. 17:1017-1020.

Galan, J. E., and Collmer, A. 1999. Type III secretion machines: Bacterial devices for protein delivery into host cells. Science 284:1322-1328.

Jones, S., Yu, B., Bainton, N. J., Birdsall, M., Bycroft, B. W., Chhabra, S. R., Cox, A. J. R., Golby, P., Reeves, P. J., Stevens, S., Winson, M. K., Salmond, G. P. C., Stewart, G. S. A. B., and Williams, P. 1993. The lux autoinducer regulates the production of exoenzyme virulence determinants in Erwinia carotovora and Pseudomonas aeruginosa. EMBO (Eur. Mol. Biol. Organ.) J. 12:2477-2482.

Lapwood, D. H., and Read, P. J. 1986. The susceptibility of stems of different potato cultivars to blackleg caused by Erwinia carotovora subsp. atroseptica. Annal. Appl. Biol. 109:555-560.

Lithgow, J. K., Wilkinson, A., Hardman, A., Rodelas, B., Wisniewski-Dye, F., Williams, P., and Downie, J. A. 2000. The regulatory locus cinRI in Rhizobium leguminosarum controls a network of quorum-sensing loci. Mol. Microbiol. 37:81-97.

Loh, J., Pierson, E. A., Stacey, L. S., and Chatterjee, A. 2002. Quorum sensing in plant-associated bacteria. Curr. Opin. Plant Biol. 5:285-290.

Mäe, A., Montesano, M., Koiv, V., and Palva, E. T. 2001. Transgenic plants producing the bacterial pheromone $N$-acyl-homoserine lactone exhibit enhanced resistance to the bacterial phytopathogen Erwinia carotovora. Mol. Plant-Microbe Interact. 14:1035-1042.

McClean, K. H., Winson, M. K., Fish, L., Taylor, A., Chhabra, S. R. Camara, M., Daykin, M., Lamb, J. H., Swift, S., Bycroft, B. W., Stewart, G. S. A. B., and Williams, P. 1997. Quorum sensing and Chromobacterium violaceum: Exploitation of violacein production and inhibition for the detection of $N$-acylhomoserine lactones. Microbiology 143:3703-3711.

Miller, M. B., and Bassler B. L. 2001. Quorum sensing in bacteria. Ann. Rev. Microbiol. 55:165-199.

Mukherjee, A., Cui, Y., Liu, Y., and Chatterjee, A. K. 1997. Molecular characterization and expression of the Erwinia carotovora hrpN (Ecc) gene, which encodes an elicitor of the hypersensitive reaction. Mol. Plant-Microbe Interact. 10:462-471.

Palva, T. K., Holmstrom, K. O., Heino, P., and Palva, E. T. 1993. Induction of plant defence response by exoenzymes of Erwinia carotovora subsp. carotovora. Mol. Plant-Microbe Interact. 6:190-196.

Perombelon, M. C. M. 2002. Potato diseases caused by soft rot erwinias: An overview of pathogenesis. Plant Pathol. 51:1-12.

Perombelon, M. C. M., Gullings-Handley, J., and Kelman, A. 1979. Population dynamics of Erwinia carotovora and pectolytic clostridia in relation to decay of potatoes. Phytopathology 69:167-173.

Piper, K. R., and Farrand, S. K. 2000. Quorum sensing but not autoinduction of Ti plasmid conjugal transfer requires control by the opine regulon and the anti-activator TraM. J. Bacteriol. 182:1080-1088.

Pirhonen, M., Flego, D., Heikinheimo, R., and Palva, E. T. 1993. A small diffusible signal molecule is responsible for the global control of virulence and exoenzyme production in the plant pathogen Erwinia carotovora. EMBO (Eur. Mol. Biol. Organ.) J. 12:2467-2476.

Rosemeyer, V., Michiels, J., Verreth, C., and Vanderleyden, J. 1998. LuxIand luxR-homologous genes of Rhizobium etli CNPAF512 contribute to synthesis of autoinducer molecules and nodulation of Phaseolus vulgaris. J. Bacteriol. 180:815-821.

Salmond, G. P. C., Bycroft, B. W., Stewart, G. S. A. B., and Williams, P. 1995. The bacterial "enigma": Cracking the code of cell-cell communications. Mol. Microbiol. 16:615-624.

Swift, S., Downie, J. A., Whitehead, N. A., Barnard, A. M. L., Salmond, G. P. C., and Williams, P. 2001. Quorum sensing as a population-density-dependant determinant of bacterial physiology. Adv. Microbiol. Physiol. 45:199-270.

Swift, S, Winson, M. K., Chan, P. F., Bainton, N. J., Birdsall, M., Reeves, P. J., Rees, C. E. D., Chhabra, S. R., Hill, P. J., Throup, J. P., Bycroft, B W., Salmond, G. P. C., Williams, P., and Stewart, G. S. A. B. 1993. A novel strategy for the isolation of luxI homologues-Evidence for the widespread distribution of a luxR luxI superfamily in enteric bacteria. Mol. Mocrobiol. 10:511-520.

Thomson, N., Evert, R. F., and Kelman, A. 1995. Wound healing in whole tubers: A cytochemical, fluorescence, and ultrastructural analysis of cut and bruise wounds. Can. J. Bot. 73:1436-1450.

Throup, J. P., Camara, M., Briggs, G. S., Winson, M. K., Chhabra, S. R., Bycroft, B. W., Williams, P., and Stewart, G. S. A. B. 1995. Characterisation of the YenI/YenR locus from Yersinia-enterocolitica mediating the synthesis of two $\mathrm{N}$-acylhomoserine lactone signal molecules. Mol. Microbiol. 17:345-356.

Toth, I. K., Thorpe, C. J., Bentley, S. D., Mulholland, V., Hyman, L. J., Perombelon, M. C. M., and Salmond, G. P. C. 1999. Mutation in a gene required for both lipopolysaccharide and enterobacterial common antigen biosynthesis affects virulence in the plant pathogen, Erwinia carotovora subspecies atroseptica. Mol. Plant-Microbe Interact. 12:499-507.

von Bodman, S. B., Dietz Bauer, W., and Coplin, D. L. 2003. Quorum sensing in plant-pathogenic bacteria. Annu. Rev. Phytopathol. 41:455-482.

Whitehead, N. A., Barnard, A. M. L., Slater, H., Simpson, N. J. L., and Salmond, G.P.C. 2001. Quorum-sensing in gram-negative bacteria. FEMS (Fed. Eur. Microbiol. Soc.) Lett. 25:365-404.

Williams, P. Camara, M., Hardman, A., Swift, S., Milton, D., Hope, V. J., Winzer, K., Middleton, B., Pritchard, D. I., and Bycroft, B. W. 2000 Quorum sensing and the population-dependent control of virulence. Philos. Trans. Roy. Soc. London B. 355:667-680.

Winson, M. K., Swift, S., Fish, L., Throup, J. P.. Jorgensen, F., Chhabra, S. R., Bycroft, B. W., Williams, P. and Stewart, G. S. A. B. (1998) Construction and analysis of luxCDABE-based plasmid sensors for investigating $N$-acyl homoserine lactone-mediated quorum sensing. FEMS (Fed. Eur. Microbiol. Soc.) Lett. 163: 185-192.

Wu, H., Song, Z. J., Givskov, M., Doring, G., Worlitzsch, D., Mathee, K., Rygaard, J., and Hoiby, N. 2001. Pseudomonas aeruginosa mutations in lasI and rhlI quorum sensing systems result in milder chronic lung infection. Microbiology 147:1105-1113. 